\title{
ORIGINAL
}

\section{BROTE DE GASTROENTERITIS EN UNA RESIDENCIA DE ANCIANOS DE ALBACETE}

\author{
José María Mayoral Cortes (1), Antonio Mateo Ramos (2), $\mathbf{M}^{\mathrm{p}}$ del Carmen Pons Sánchez (1), Isabel \\ Herrera Calvet (3), Guillermo Gutiérrez Avila (4), Amparo Vivo (3), Marcelino García Fernández (1), \\ Dionisio Herrera Guibert (1) y Ferrán Martínez Navarro (5)
}

(1) Programa de Epidemiología Aplicada de Campo. Centro Nacional de Epidemiología.

(2) Delegación de Salud Albacete.

(3) Centro Nacional de Microbiología.

(4) Consejería de Sanidad de Castilla la Mancha.

(5) Centro Nacional de Epidemiología

\section{RESUMEN}

Fundamento: Se describe el estudio de un brote de gastroenteritis aguda de inicio explosivo y probable origen hídrico, en una residencia de ancianos de Albacete, en el mes de noviembre de 1999 y que afectó a 104 residentes y a 35 trabajadores. El cuadro clínico se caracterizó por la presentación de vómitos y diarrea como síntomas dominantes.

Métodos: Se diseñó un estudio de casos y controles. Se realiza un análisis descriptivo de datos y cruce de variables mediante tablas simples. El análisis multivariante se realiza mediante modelos de regresión logística para la fase explosiva y de transmisión de persona a persona.

Resultados: La tasa de ataque fue del $45,8 \%$ para residentes y de $33,7 \%$ en trabajadores. Se encontró asociación entre la utilización del comedor principal de la residencia y el inicio explosivo del brote así como entre la presencia inicial de un caso en habitaciones compartidas y la transmisión de persona a persona. Se aisló virus Norwalk-like en heces de 4 enfermos.

Conclusiones: El análisis de las características clínicas y epidemiológicas, así como los resultados de laboratorio confirman la implicación del virus Norwalk-like como agente causal en este brote.

Palabras clave: Brote epidémico. Gastroenteritis vírica. Virus Norwalk-like. Ancianos.

\section{ABSTRACT}

\section{Outbreak of Gastroenteritis at an Old People's Home in Albacete}

Background: We describe the investigation of an acute gastroenteritis outbreak with an explosive beginning, probably waterborne, that ocurred in an nursing home in Albacete, in November 1999 and affected 104 inmates and 35 employees. The dominant symptoms were diarrhea and vomiting.

Methods: A case-control study was designed. We carried out a descriptive analysis of facts and crossing of variables with the help of simple tables. A multivariant analysis, by models of logistic regression, was conducted both for the explosive phase and for that of transmission person-to-person.

Results: The attack rate for inmates was $45,8 \%$ and for employees,33,7\%. An association was found between the use of the main dining-room of the nursing home and the explosive beginning of the outbreak and between the previous presence of a case-patient in the shared bedrooms and the person-to-person transmission. Norwalk-like virus was isolated from faeces samples of four cases.

Conclusions: The analysis of the clinical and epidemiological findings as well as the laboratory results proved the implication of a Norwalk-like virus in this outbreak.

Key words: Epidemic outbreak. Viral gastroenteritis. Norwalk-like virus. Nursing home.

\section{INTRODUCCIÓN}

Correspondencia:

José María Mayoral Cortés.

C/ Miguel de Cervantes, 2

Sanlúcar la Mayor

41800 Sevilla

Correo electrónico:jmmc@ cica.es
El envejecimiento de la población y el aumento de personas ingresadas en residencias de ancianos, muchas de ellas con problemas de salud, favorecen las condiciones necesarias 
para la aparición de brotes de gastroenteritis aguda (GEA) dentro de estas instituciones ${ }^{1-3}$. Los sistemas de vigilancia epidemiológica, adaptados para estudio de los brotes de GEA en residencias de ancianos, existentes en países de nuestro entorno ${ }^{4-7}$, han permitido conocer más detalladamente las características epidemiológicas y agentes causales más comúnmente implicados y han constatado la elevada morbimortalidad por GEA en este grupo de población anciana, debido, entre otras razones, a las elevadas tasas de ataque y duración de los brotes y a las características de riesgo de este grupo de población, encontrándose los virus enteropatógenos, entre ellos los calicivirus, como los agentes causales implicados con mas frecuencia en estos brotes.

Entre los días 4 y 17 de noviembre se produjo un brote de gastroenteritis aguda (GEA), de inicio explosivo, en una residencia de ancianos de Albacete con 237 residentes y 104 trabajadores. El estudio epidemiológico se inició el 23 de noviembre y tuvo como objetivo investigar las causas y factores determinantes de su origen y transmisión, con el fin de conocer el comportamiento de estos brotes dentro de instituciones cerradas que ayude a adoptar medidas futuras para su vigilancia y prevención.

\section{SUJETOS Y MÉTODOS}

Se realizó un estudio descriptivo del brote y se planteó para su análisis un diseño de casos y controles ${ }^{8-9}$, definiendo como caso a cualquier persona, residente o trabajador del centro, que hubiese presentado vómitos y/o diarrea entre los días 4 y 17 de noviembre de 1999, con o sin otros síntomas o signos acompañantes de GEA y sin ninguna patología de base que lo justificara. A criterio de los autores, teniendo en cuenta la duración de la exposición y el periodo de incubación, se consideraron como casos coprimarios a todos los sujetos que enfermaron durante los primeros 2 días del brote y aquellos que enfermaron durante el $3^{\text {er }}$ día, siempre que no compartie- sen habitación o módulo con otro residente que hubiese enfermado al menos 24 horas antes. Se han considerado casos secundarios a los sujetos que enfermaron a partir del $4^{\circ}$ día y los de aquéllos que enfermaron durante el $3^{\text {cr }}$ día compartiendo habitación o módulo con un caso aparecido al menos 24 horas antes. Las recaídas se definieron como la aparición en un caso de un nuevo episodio de GEA tras intervalo de al menos 4 días libre de síntomas y dentro del periodo epidémico. Como controles se tomaron a los residentes y trabajadores sin síntomas de GEA durante el periodo de estudio.

Fueron excluidos del estudio residentes y trabajadores que hubiesen permanecido fuera de la residencia durante el periodo epidémico y aquellos residentes que presentaban vómitos y/o diarrea atribuible a alguna patología de base.

Las fuentes de información para la clasificación de los casos y controles fueron los registros de enfermería y los libros diarios de incidencia existentes en cada planta y unidades especificas de la residencia. Se elaboró una encuesta epidemiológica, que fue cumplimentada para cada uno de los 227 residentes incluidos en el estudio, 104 casos y 123 controles, con información referida a las características personales, aparición y duración de la enfermedad, así como de los factores que se consideraron que podrían estar implicados en la aparición y extensión del brote: comidas realizadas, agua consumida, contactos, etcétera. Si bien se recogían en el cuestionario los menús servidos durante los días que precedieron al brote, no se incluyeron de manera detallada los alimentos y cantidades consumidas, debido a la lejanía en el tiempo entre el estudio y la exposición, además de las características de la población estudiada. Aquellos factores contemplados en el cuestionario que podrían asociarse al inicio explosivo del brote fueron referidos a las 24-48 horas antes de su inicio. El mismo cuestionario adaptado fue distribuido entre los 35 trabajadores enfermos y 69 controles incluidos en el estudio. 
El análisis descriptivo de los datos y cruce de variables mediante tablas simples y estratificadas fue realizado con el programa informático Epi-Info v.6. ${ }^{10}$. El análisis multivariante con el programa Logistic v. 3.11 Ef. ${ }^{11}$.

Durante los tres primeros días del brote se tomaron, en tarros estériles, muestras de heces, obtenidas por emisión directa, de 5 residentes que presentaban síntomas de GEA. El cuarto día del brote se recogieron muestra de heces de un manipulador que enfermó. De los mismos pacientes se recogieron sueros pareados de fase aguda y convaleciente (3 semanas después del inicio de síntomas). Las muestras de heces y sueros fueron recogidas y conservadas siguiendo las recomendaciones establecidas por el Centro Nacional de Microbiología (CNM) del Instituto de Salud Carlos III ${ }^{12}$, donde fueron enviadas, además de al laboratorio provincial de salud pública, para su análisis.

Durante la primera semana del brote la sección de sanidad ambiental y de higiene de los alimentos de la Delegación de Salud de Albacete recogió muestras de alimentos congelados, preparados y servidos durante los días 4 y 5 de noviembre para su análisis microbiológico y muestras de agua procedentes de la red en diferentes puntos del edificio (depósito subterráneo, office de $1^{\text {a }}$ y $3^{\mathrm{a}}$ planta y grifos de agua fría y caliente de cocina) y de un depósito de la $4^{\mathrm{a}}$ planta, con agua tratada de forma independiente a la red mediante osmosis inversa, para el análisis de sus características microbiológicas, organolépticas y físico-químicas en el laboratorio provincial de salud pública, según la normativa vigen$t^{13}$. Las dificultades técnicas existentes, impidieron el estudio de virus en muestras de agua.

\section{RESULTADOS}

La residencia de Albacete tiene cinco plantas con habitacioncs individuales, dobles y módulos de 2 y 4 habitaciones que compar- ten baño. En la planta baja se ubican los servicios generales de la residencia, la residencia de día que atiende a 17 ancianos y la Unidad de Cuidados Especiales (UCE) con 16 ancianos ingresados. En estas dos unidades la relación con el resto de residentes es exclusivamente a través de aquellos que acuden a fisioterapia o terapia ocupacional y del personal que los atiende.

Dispone de una sola cocina y de 9 comedores, cinco situados en la planta baja (Principal, trabajadores, residencia de día, UCE y cafetería) y uno por planta, en todos ellos a excepción de la cafetería, el menú es preparado y servido desde la cocina central. El menú se programa con una semana de antelación y es el mismo para los residentes y trabajadores.

El agua de consumo procede de la red de abastecimiento general de Albacete y se distribuye por todas las dependencias de la residencia, almacenándose antes de su entrada en el edificio en un aljibe enterrado. Para reducir la dureza del agua, la residencia dispone de un sistema de ósmosis inversa, con un depósito en la $4^{a}$ planta, en el que se utiliza como método de desinfección una lampara superficial de radiación ultravioleta. La distribución de este agua se realiza a través de un circuito independiente de la red general, con un único grifo de salida en un extremo cerrado de cada planta, estando el de la planta baja situado en la cocina.

Entre los 227 residentes incluidos en el estudio, 104 presentaron síntomas de GEA con criterios de inclusión de caso, con una tasa de ataque global del $45,8 \%$. La tasa de ataque en trabajadores fue del $33,7 \%$. La edad de los residentes sigue una distribución normal con media, mediana y moda de 80 años. La edad media fue de 80,8 años $(\mathrm{DE}=8,5)$ para los casos y de 79,7 años ( $\mathrm{DE}=7,7$ ) para los controles, no existiendo diferencias significativas entre ambos grupos para la edad $(\mathrm{p}=0,29)$. Entre los residentes, 147 eran mujeres, de las cuales 74 enfermaron, y 80 eran varones de los cuales enfermaron 30. Las tasa de ataque especifica para las mujeres fue del $50,3 \%$ y 


\section{Figura 1}

Distribución por grupos de edad. Total de residentes y enfermos

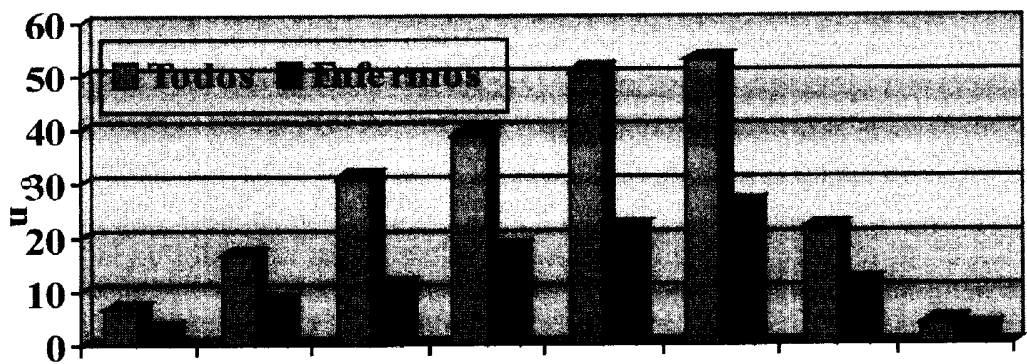

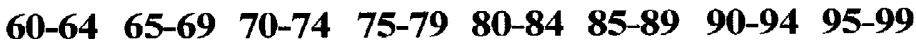

$37,5 \%$ entre los varones $(\mathrm{OR}=1,69 ; \mathrm{IC} 95 \%=$ $0,93-3,08 ; p=0,06)$. Las distribuciones por grupos de edad y sexo de los casos y de todos los residentes y las tasas de ataque por grupos de edad y sexo, se exponen en la figura 1 y tabla 1 .

\section{Tabla 1}

Tasas de Ataque entre residentes por grupos de edad y sexo

\begin{tabular}{|c|c|c|}
\hline Grupos de Edad & Varones & Mujeres \\
\hline $60-69$ & 33,3 & 48,6 \\
\hline $70-79$ & 34,4 & 51,3 \\
\hline $80-99$ & 85,7 & 47,4 \\
\hline
\end{tabular}

Los síntomas y signos presentes en los casos se recogen en la tabla 2. Destacan por su frecuencia vómitos $(89,9 \%)$, diarrea $(82,0 \%)$ y nauseas $(76,4 \%)$. Los casos con fiebre $(18,3 \%)$ nunca superaron $\operatorname{los} 38^{\circ} \mathrm{C}$.

Los primeros casos aparecieron en residentes el día 4 de noviembre a partir de las 20 horas y los últimos el día 14. Los casos en trabajadores se presentaron entre los días 6 y 17 de noviembre. En la curva epidémica (fi-
Tabla 2

Síntomas y Signos en residentes y trabajadores enfermos

\begin{tabular}{|l|c|c|}
\hline & $N$ & $\%$ \\
\hline Vómitos & 116 & 89,9 \\
\hline Malestar general & 70 & 84,3 \\
\hline Diarrea & 105 & 82,0 \\
\hline Nauseas & 81 & 76,4 \\
\hline Cefalea & 49 & 63,3 \\
\hline Dolor abdominal & 39 & 44,3 \\
\hline Fiebre & 20 & 18,3 \\
\hline
\end{tabular}

guras 2, 3 y 4) se observa un ascenso rápido del numero de casos en las primeras 24 horas, con un numero elevado entre el $2^{\circ}$ y $4^{\circ}$ día del brote y una caída progresiva en los días sucesivos.

Los casos coprimarios entre residentes fueron 36 , con una tasa de ataque del 15,9\%, mientras que los secundarios fueron 68 , lo que se corresponde a una tasa de ataque secundario del $35,6 \%$. 
Figura 2

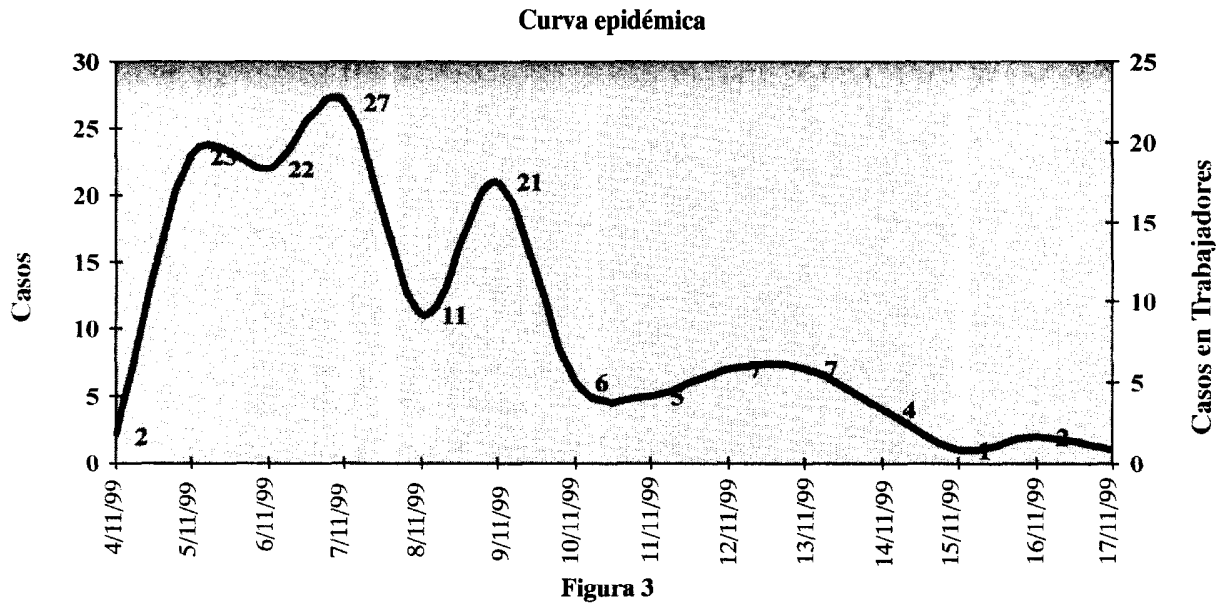

Curva epidémica en residentes y trabajadores

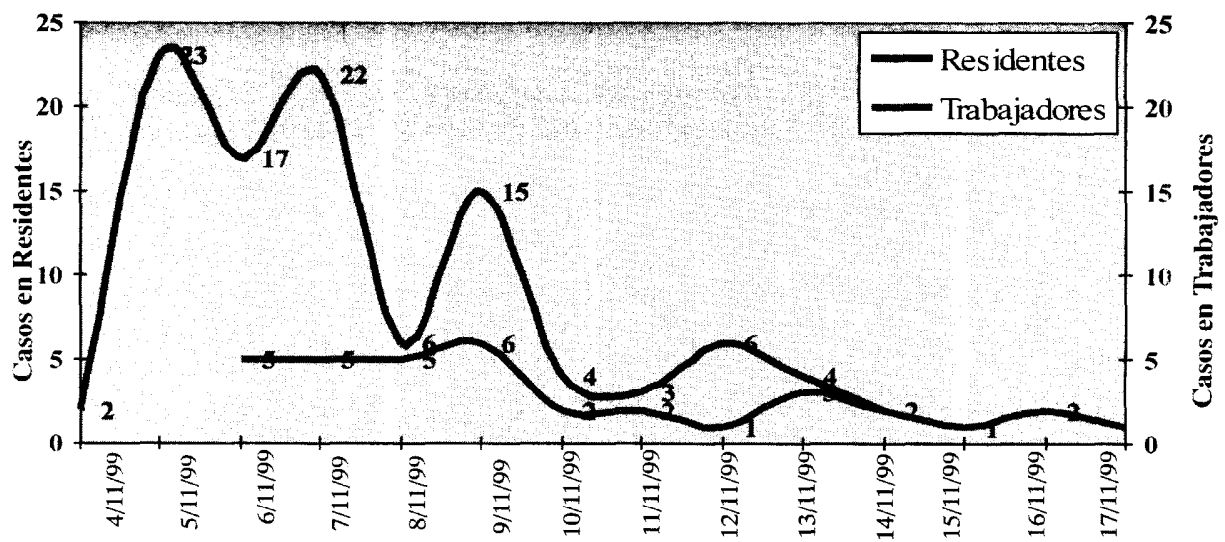

Figura 4

Explosión y transmisión en residentes

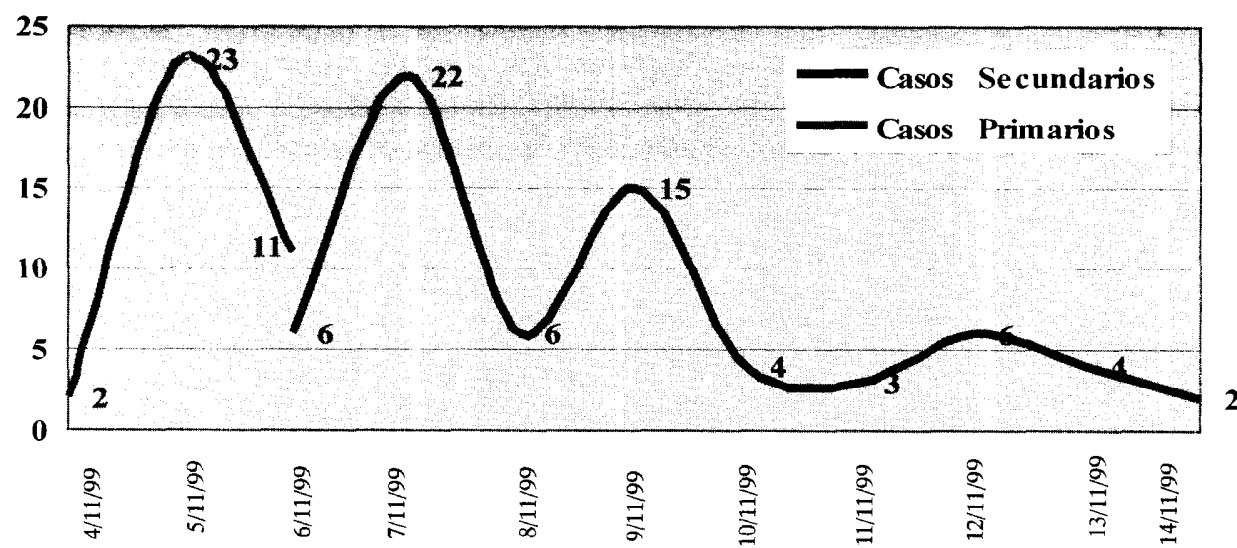


La figura 4 se ha construido tomando el criterio de caso coprimario y secundario y muestra las curvas de la fase explosiva y de transmisión entre los residentes. Entre los trabajadores (figura 3), los primeros casos aparecieron durante el tercer día del brote con un numero constante de casos durante los 3 primeros días.

A partir del tiempo medio transcurrido entre la existencia de casos primarios y la aparición de casos secundarios entre los residentes en módulos y habitaciones dobles, se ha estimado un periodo de incubación de 8 a 60 horas (media de 32 y mediana de 27 1/2 horas).

La probabilidad de enfermar entre los residentes durante todo el periodo del brote, re- lacionada con las variables principales incluidas en el estudio se expone en la tabla 3. En el análisis univariante, se encuentra asociación entre la aparición de la enfermedad con haber comido en el comedor principal frente al resto de comedores $(\mathrm{OR}=2,03$; IC$95 \%=1,13-3,63 ; \mathrm{p}=0,01)$, residir en una planta diferente de la baja $(\mathrm{OR}=7,71$; IC$95 \%=2,43-27,23 ; \mathrm{p}<0,000)$ y haber compartido habitación o módulo con un caso previo $(\mathrm{OR}=3,31 ; \mathrm{IC}-95 \%=1,72-6,4 ; \mathrm{p}=0,01)$. El agua consumida por los residentes es la servida en jarras en los comedores procedente de la red y el 91,6\% también consume habitualmente agua de la red fuera de los comedores. Entre los trabajadores el $82,7 \%$ declaró consumir habitualmente agua embotellada.

Tabla 3

Riesgo de enfermar en ancianos residentes, durante todo el periodo epidémico según diferentes variables de exposición. Análisis univariante

\begin{tabular}{|c|c|c|c|c|c|c|}
\hline & \multicolumn{2}{|c|}{ Casos } & \multicolumn{2}{|c|}{ Controles } & \multicolumn{2}{|c|}{ Análisis thivariante } \\
\hline & Sí & NO & Sí & NO & OR $(I C 95 \%)$ & $p$ \\
\hline Sexo femenino & 74 & 30 & 73 & 50 & $1,69(0,93-3,08)$ & 0,06 \\
\hline Dependencia & 39 & 64 & 45 & 76 & $1,03(0,57-1,85)$ & NS \\
\hline Autonomía Movilidad & 42 & 62 & 44 & 77 & $1,19(0,66-2,12)$ & NS \\
\hline Aulonomía Higiene & 57 & 47 & 68 & 53 & $0,95(0,54-1,67)$ & NS \\
\hline Control Esfínteres & 39 & 64 & 55 & 66 & $0,73(0,41-1,30)$ & NS \\
\hline Dieta Básica & 86 & 18 & 100 & 23 & $1,10(0,52-2,31)$ & NS \\
\hline Comedor Principal & 70 & 34 & 62 & 61 & $2,03(1,13-3,63)$ & 0,01 \\
\hline Planta distinta a Baja & 100 & 4 & 94 & 29 & $7,71(2,43-27,23)$ & $<0,000$ \\
\hline Habitación o módulo compartido & 89 & 15 & 98 & 25 & $1,51(0,71-3,26)$ & NS \\
\hline $\begin{array}{l}\text { Compañero de módulo o } \\
\text { habitación enfermo }\end{array}$ & 77 & 22 & 55 & 52 & $3,31(1,72-6,4)$ & 0,01 \\
\hline Edad Media & \multicolumn{2}{|c|}{80,8} & \multicolumn{2}{|c|}{79,7} & & NS \\
\hline
\end{tabular}


Durante la fase explosiva (casos coprimarios) y la fase de transmisión (casos secundarios), la probabilidad de enfermar en función de las variables consideradas se exponen en la tabla 4, quedando bien diferenciados los factores que influyen en la aparición y transmisión de la enfermedad. El antecedente de haber comido en el comedor principal está relacionado con la aparición de los casos durante el inicio explosivo del brote, mientras que la presencia de un caso previo en habitaciones o módulos compartidos se relaciona con una mayor probabilidad de aparición de nuevos casos durante la fase de transmisión persona a persona.

Tabla 4

Riesgo de enfermar en ancianos residentes, durante el periodo explosivo y de transmisión persona a persona, según diferentes variables de exposición. Analisis univariante

\begin{tabular}{|l|c|c|c|c|}
\hline \multirow{2}{*}{} & \multicolumn{2}{|c|}{ Fase explosiva } & \multicolumn{2}{c|}{ Fase de transmisión } \\
\cline { 2 - 5 } & OR (IC 95\%) & $P$ & OR (IC 95\%) & $p$ \\
\hline Edad & & NS & & NS \\
\hline Sexo femenino & $2,56(1,10-6,58)$ & 003 & $1,34(0,69-2,62)$ & NS \\
\hline Dependencia & $0,93(0,41-2,08)$ & NS & $1,07(0,55-2,08)$ & NS \\
\hline Autonomía Movilidad & $1,19(0,54-2,61)$ & NS & $1,15(0,59-2,23)$ & NS \\
\hline Autonomía Higiene & $1,00(0,46-2,19)$ & NS & $0,93(0,49-1,78)$ & NS \\
\hline Control Esfínteres & $1,04(0,47-2,31)$ & NS & $0,65(0,34-1,27)$ & NS \\
\hline Dieta Básica & $1,12(0,40-3,29)$ & 18 & $1,07(0,46-2,51)$ & NS \\
\hline Comedor Principal & $4,36(1,62-12,39)$ & $<0,000$ & $1,41(0,74-2,69)$ & NS \\
\hline Planta distinta a Baja & $7,52(1,17-314,2)$ & 0,02 & $4,94(1,53-17,63)$ & $<0,000$ \\
\hline Habitación o módulo compartido & $1,86(0,57-6,70)$ & NS & $1,32(0,57-3,13)$ & NS \\
\hline Compañero de módulo o habitación enfermo & $2,46(0,94-6,66)$ & 22 & $3,15(1,49-6,73)$ & $<0,000$ \\
\hline
\end{tabular}

Residir en la planta baja aparece como un factor de protección frente a la enfermedad en cualquiera de las dos fases descritas del brote.

El análisis multivariante mediante regresión logística (tabla 5) muestra que la probabilidad de enfermar durante la fase explosiva, ajustada por el resto de variables incluidas en el modelo, es mayor $(p<0,0001)$ entre los que comieron en el comedor principal frente a los que utilizan otros comedores. Ningún residente de la planta baja enfermó durante la fase explosiva, por lo que esta variable no ha sido incluida en el modelo. Durante la fase de transmisión el riesgo de enfermar entre los residentcs que 
compartían módulo o habitación doble, donde ya había aparecido un caso, es mayor $(p<0,01)$ que en el resto, excluyendo del análisis las habitaciones individuales y residentes de día.

Tabla 5

Riesgo de enfermar en ancianos residentes, durante el periodo explosivo y de transmisión persona a persona, según diferentes variables de exposición. Analisis multivariante

\begin{tabular}{|l|c|c|c|c|}
\hline \multirow{2}{*}{} & \multicolumn{2}{|c|}{ Fase explosiva } & \multicolumn{2}{c|}{ Fase de transmisión } \\
\cline { 2 - 5 } & OR (IC 95\%) & $P$ & OR (IC 95\%) & $p$ \\
\hline Sexo femenino & $3,9(1,57-9,68)$ & 0,01 & - & - \\
\hline Planta distinta a Baja & - & - & - & - \\
\hline Comedor Principal & $5,97(2,31-15,42)$ & $<0,000$ & - & - \\
\hline Planta Baja & - & - & $0,19(0,02-1,79)$ & $\mathrm{ns}$ \\
\hline Compañero de módulo o habitación enfermo & - & - & $3,14(1,20-10,19)$ & 0,01 \\
\hline
\end{tabular}

La frecuentación del comedor principal difiere por sexos; el $48 \%$ de las mujeres come habitualmente en este comedor, frente al $75 \%$ de los hombres $(\mathrm{p}<0,001)$. Sin embargo, durante la fase explosiva el $59,4 \%$ de las mujeres que comieron en este comedor enfermaron, frente al $24,1 \%$ de los hombres, mientras que la probabilidad de enfermar fue similar para ambos sexos $(6 \%$ varones y $5 \%$ mujeres) entre los residentes que no acuden al comedor principal. La estimación del riesgo de enfermar entre los residentes que comieron en el comedor principal se incrementa cuando se realiza un ajuste del lugar donde se produjo la exposición por sexo (tablas 4 y 5).

Ningún trabajador de la residencia enfermó durante el periodo explosivo del brote y no se observaron diferencias importantes en la incidencia de la enfermedad entre los trabajadores asistenciales (auxiliares, médicos, etc.) y los de la limpieza, con una tasa de ataque de $39,5 \%$. Sin embargo, entre el personal de administración de la residencia no hubo constancia de ningún caso de GEA durante todo el periodo epidémico.

En los análisis realizados por el laboratorio provincial de salud pública no se aisló ningún germen patógeno en los alimentos, ni en las muestras de heces analizadas de los enfermos. El CNM identificó, mediante microscopía electrónica, calicivirus Norwalklike en muestras de heces de 2 residentes enfermos y la inmunoconversión fue positiva en otros 2 casos de residentes, descartándose la presencia, en las muestras obtenidas entre residentes, de otros agentes víricos (adenovirus y rotavirus) o bacterianos (Salmonella, Shigella, E. Coli, Campylobacter; Staphylococcus).

El análisis de agua procedente de la red de abastecimiento general mostró un buen estado de cloración con valores de cloro residual superiores a $0,3 \mathrm{mg} / \mathrm{l}$ en los puntos muestreados. Las determinaciones organolépticas, microbiológicas y físico-químicas 
fueron normales, a excepción de una presencia elevada de sulfatos y sodio. En las muestras del deposito de agua de la $4^{\mathrm{a}}$ planta, tratada mediante el dispositivo de ósmosis inversa, se observó ausencia de cloro residual libre y aumento de los parámetros nitritos y amonio, compatibles con la presencia de contaminación orgánica, y se constató la ausencia de reposición de cloro tras el tratamiento de ósmosis.

\section{DISCUSIÓN}

Los brotes por virus enteropatógenos, entre ellos los calicivirus, se han asociado a una exposición a fuente común hídrica ${ }^{14-16} \mathrm{o}$ a diversos alimentos de consumo crudo, entre los cuales las verduras, frutas frescas, mariscos y la preparación de comidas por manipuladores infectados, son los más conoci$\operatorname{dos}^{17-19}$. Si bien el inicio explosivo es el más frecuente, la propagación mediante transmisión de persona a persona vía oro-fecal esta bien documentada ${ }^{3,20}$.

La curva epidémica, con un ascenso rápido del número de casos durante los primeros días y descenso progresivo en los días siguientes, corresponde a un brote explosivo provocado por la exposición a una fuente común y con un corto periodo de incubación, seguido de una transmisión de persona a persona.

La curva epidémica entre los trabajadores corresponde a una transmisión de persona a persona, la aparición de los primeros caso a partir del tercer día del brote es compatible con la hipótesis de su contagio a partir del contacto con múltiples residentes enfermos de diferentes plantas, fundamentalmente durante los primeros tres días del brote, sin que pueda establecerse con exactitud el momento y lugar de la exposición.

Un periodo de incubación medio de 32 horas es compatible con la hipótesis de que el brote tuvo su origen tras una exposición común en el comedor principal, durante la comida del día 4 de noviembre, apareciendo el primer caso 7 u 8 horas después y con una agrupación temporal de casos bien definida en las 44-72 horas posteriores, prolongándose el brote durante 14 días hasta finalizar de manera espontanea.

Tres hipótesis podrían explicar el inicio del brote en el comedor principal:

1. La existencia de una exposición inicial masiva a un alimento contaminado ${ }^{17.19}$ sólo en este comedor, poco probable, pues los menús servidos son los mismos en todos los comedores de la residencia, a excepción de la cafetería, y se elaboran al mismo tiempo en una sola cocina central, por los mismos manipuladores de alimentos.

2. Las características sanitarias encontradas en el agua de la red general y las diferencias en la distribución espacial y temporal de casos hacen que sea poco probable la implicación del agua de la red como vehículo de transmisión de la enfermedad ${ }^{14-16}$. En el comedor principal, como en el resto de comedores, con excepción del comedor de trabajadores en el que se sirve agua embotellada, el agua es servida por auxiliares y procede habitualmente de la salida de la red general.

3. La utilización accidental y puntual, durante una comida en el comedor principal, de agua procedente del dispositivo de osmosis inversa, podría haberse producido por la presencia de la única salida de agua procedente de este dispositivo en la cocina junto al grifo de la red que se utiliza habitualmente para servir el agua en el comcdor principal. La concentración de residentes en este comedor y la contaminación orgánica encontrada en el agua del depósito de distribución de este dispositivo podría justificar esta hipótesis causal. Este sistema, en desuso en la residencia durante el último año, carecía de controles sanitarios establecidos, no reponiéndose cloro al agua almacenada del deposito tras el tratamiento de ósmosis inversa y aplicándose radiación ultravioleta superficial para su desinfección. La existencia de dispositivos internos de distribución de agua, distintos a la red de distribu- 
ción general y con un control deficiente, suponen un riesgo evidente para la aparición de brotes epidémicos de origen hídrico dentro de instituciones cerradas.

En la planta baja, donde se ubican la unidad de cuidados especiales y residencia de día, el número de casos durante todo el periodo epidémico fue de 4 , con una tasa de ataque del $12,1 \%$. La baja incidencia entre estos residentes refuerza la hipótesis del origen del brote en el comedor principal por exposición a una fuente común y transmisión posterior de persona a persona. Estos residentes comen dentro de sus servicios, beben agua procedente de la red general y mantienen una relación restringida con el resto de residentes. Entre ellos no hubo ningún caso durante la fase explosiva, apareciendo el primer caso en el día $8^{\circ}$ del brote, con posterioridad a un caso previo de un residente que duerme en otra planta pero que come habitualmente en este servicio (UCE) o a trabajadores enfermos en ambos servicios.

El cuadro clínico que presentaron los enfermos, con vómitos y diarrea de 24 a 48 horas de duración como síntomas predominantes, el periodo de incubación medio, la duración del brote y la elevada tasa de ataque secundario, son compatibles con la presentación característica de los brotes provocados por calcivirus $^{21}$. La identificación por el laboratorio del CNM de virus de Norwalk en muestras biológicas de 4 residentes enfermos hace probable su implicación como agente causal del brote epidémico.

En España, durante los últimos 10 años, son escasas las publicaciones de estudios de brotes causados posiblemente por calicivirus $1^{4,18}$ y ninguno de ellos estuvo relacionado con residencias de ancianos. Sin embargo, diversos estudios ${ }^{3-7}$ han puesto de manifiesto la implicación de los virus Norwal-like y otros calicivirus, como agentes causales más frecuentes en los brotes de GEA en residencias de ancianos.

No se ha descrito el estado de portador para los virus Norwalk-like, sin embargo es- tudios de seroprevalencia en situaciones de brotes, han demostrado una elevada presencia de anticuerpos en individuos asintomáticos, lo que sugiere que las infecciones subclínicas son muy comunes ${ }^{22}$. En este brote los posibles casos subclínicos fueron clasificados como sanos en el estudio de casos y controles, aunque su importancia es relativa en la medida que una clasificación correcta incrementaría las diferencias en las estimaciones observadas entre los casos y los controles.

Una de las limitaciones a considerar en este estudio son los sesgos de recuerdo derivados del tiempo transcurrido entre la exposición, el comienzo del brote y el inicio del estudio en una población anciana. Sin embargo, el uso habitual del agua de red, recogida de diferentes puntos para cada uno de los comedores, como única bebida durante las comidas de los residentes, la existencia de una sola cocina central, la uniformidad en el proceso de elaboración de las comidas servidas entre todos los residentes y la recogida de la información a partir de los registros diarios de incidencia de cada planta, cumplimentados por el personal auxiliar encargado del cuidado de los ancianos, pueden limilar la importancia de la encuesta alimentaria para estudiar el vehículo de transmisión.

La elevada tasa de ataque secundario y el periodo epidémico de dos semanas de duración hacen muy probable que la finalización del brote fuera por agotamiento de sujetos susceptibles, hecho que también ha sido constatado en brotes similares en residencias de ancianos ${ }^{4,23,24} \mathrm{e}$ implica un elevado riesgo de morbimortalidad para la población anciana residente en instituciones cerradas. La vigilancia epidemiológica de GEA en residencias de ancianos mediante sistemas simples y factibles, el entrenamiento y la educación sanitaria del personal que atiende a esta población, así como la intervención de profesionales expertos que asegure un control rápido de estos brotes, serían medidas a adoptar para su prevención y control efectivo. 


\section{AGRADECIMIENTOS}

A los profesionales de la residencia de ancianos y de la Delegación de salud de $\mathrm{Al}-$ bacete, por su disponibilidad y colaboración en la investigación de este brote. A los técnicos del servicio de microscopía del Centro Nacional de Microbiología por el estudio de laboratorio.

\section{BIBLIOGRAFÍA}

1. Smith JL. Foodborne Illness in the elderly. J Food Prot 1998 61(9): 1229-1239.

2. Jackson MM, Fierer J. Infections and infection risk in residents of long-term care facilities: Review of the literature. 1970-1984. Am J Infect Control 1985; 13: 63-67.

3. Marx A, Shay DK, Noel JS, et all. An outbreak of acute gastro-enteritis in a geriatric longterm-care facility: combined application of epidemiological and molecular diagnostic methods. Infect Control Hosp Epidemiol 1999 May; 20 (5): 306-311.

4. Ryan MJ, Wall PG, et all. Outbreaks of Infectious Intestinal Disease in Residential Institutions in England and Wales. 1992-1994. J Infect 1997, 34: 49-54.

5. Cowden JM, Wall PG, Adak G, ct all. Outbreaks of foodborne infectious intestinal disease in England and Wales: 1992 and 1993. Commun Dis Rep CDR Rev 1995 Jul 21; 5(8): R109-117.

6. Djuretic T, Wal PG, Ryan MJ et all. General outbreaks of infectious intestinal discasc in England and Wales 1992 to 1994. Commun Dis Rep CDR Rev 1996 Mar 29; 6 (4): R57-63.

7. Evans HS; Madden P; Douglas C; Adad GK; et all. General outbreaks of infectious intestinal disease in England and Wales:1995 and 1996. Commun Dis Public Health 1998; 1(3): 165 71.

8. Kelsey JL, Thompson ND. Methods in observational epidemiology. Nueva York: Oxford University Press;1986.p. 10-11.

9. Holland W, Detels R, Knox G. Oxford Text Book of Public Health, vol 3. Investigative methods in public health. Nueva York: Oxford University Press;1991.p.101-112.

10. Dean AG, Dean JA, Colombier D, et al. Epi Info version 6: a word processing, database and statistics programme for epidemiology on microcomputcrs. Gcorgia: Centers for Control and Prevention; 1994.

11. Quigley M, Myatt M. Don't Panic. A guide to statistical methods for outbreaks investigation. London: Brixton Book; 1994.

12. Vivo Rodríguez A, Herrera Calvet MI, Fernández Campo A, et all. Gastroenteritis víricas. Diagnostico de brotes por virus esféricos de pequeño tamaño, en especial calicivirus "Norwalk-like". Bol Epidemiol Sem1999; 7 (11); 117-118.

13. Boletín Oficial de Estado. Real Decreto 1138/1990, de 14 de septiembre, por el que se aprueba la Reglamentación Técnico-sanitaria para el abastecimiento y control de calidad de las aguas potables de consumo público. BOE núm 226 de 20/09/90.

14. Chover Lara JL, Pastor Vicente S., Roig Sena FJ et all. Brote de Gastroenteritis asociado al consumo de agua, posiblemente producido por virus de Norwalk o semejantes. Rev Esp Salud Publica 1995; 69: 343-254.

15. Brugha R, Vipond IB, Evans MR, et all. A community outbreak of food-borne small round-structure virus gatroenteritis caused by contaminated water supply. Epidemiol Infect 1999; 122 (1): 145-54.

16. Kukkula M, Arstila P, Klossner ML, et all. Waterborne outbreak of viral gatroenteritis. Scand J Infect Dis 1997; 29 (4): 415-418.

17. Norwalk-like Viral Gastroenteritis in U.S. Army Trainees. Texas 1998. MMWR 1999; 48(11); 225-227.

18. Arnedo Peña A, González Morán F, Bellido Blasco J, et all. Brote de intoxicación alimentaria de probable etiología vírica por virus Norwalk. Gac Sanit 1991 Jul-Aug; 5(25): 169-173.

19. Pönkä L, Maunula $\mathrm{CH}$, et all. Epidémie d'infections à calcivirus associée à la consommation de framboises congéeles. Eurosurveillance 1999; 4 (6): 66-69.

20. Cáceres VM, Kim DK, Bresee JS, et all. A viral gastro-enteritis outbreak associate with person- 
to-person spread among hospital staff. Infect Control Hosp Epidemiol 1998;19 (3): 162-167.

21. Kaplan J, Gary GW, Douglas S, Campbell D, et al. The frequency of Norwalk-like patherm of Illness in outbreaks of acute gastro-enteritis. Am J Public Hcalth 1982; 72: 1329-32.

22. Treanor J, Dolin R. Virus Norwalk y otros calicivirus. En: Mandell, Douglas, Bennett, editores. Enfermedades infecciosas. Principios y practica. $4^{a}$ ed. en español. Buenos Aires: Editorial Médica Panamericana; 1997. p.1867-73.
23. González Pérez, LC. Coll Jordá, D. Gómez de Caso Canto, JA. Martínez Navarro, F. Brote de Gastroenteritis en una residencia asistida de Ancianos de Segovia. Programa de Epidemiología Aplicada de Campo. Centro Nacional de Epidemiología; 1995. Informe técnico.

24. Segura del Pozo J, Velázquez Buendía L, Martínez Navarro F. Brote de Gastroenteritis en una Residencia de Ancianos de Alcalá de Henares. Programa de Epidemiología Aplicada de Campo. Centro Nacional de Epidemiología; 1999. Informe técnico. 